\title{
Unsolved matters in leprosy: a descriptive review and call for further research
}

\author{
Carlos Franco-Paredes ${ }^{1,2^{*}}$ and Alfonso J. Rodriguez-Morales ${ }^{3}$
}

\begin{abstract}
Leprosy, a chronic mycobacterial infection caused by Mycobacterium leprae, is an infectious disease that has ravaged human societies throughout millennia. This ancestral pathogen causes disfiguring cutaneous lesions, peripheral nerve injury, ostearticular deformity, limb loss and dysfunction, blindness and stigma. Despite ongoing efforts in interrupting leprosy transmission, large numbers of new cases are persistently identified in many endemic areas. Moreover, at the time of diagnosis, most newly identified cases have considerable neurologic disability. Many challenges remain in our understanding of the epidemiology of leprosy including: (a) the precise mode and route of transmission; (b) the socioeconomic, environmental, and behavioral factors that promote its transmission; and (c) strategies to achieve early diagnosis and prevent neurologic impairment to reduce the large burden of disability among newly identified cases; and among those who endure long-term disability in spite of completing multidrug therapy.
\end{abstract}

Keywords: Leprosy, Mycobacterium leprae, Hansen's disease, Sequelae, Peripheral nerve, Schwann cell, Histiocytes, Leprosy reactions, Disability, Elimination

\section{Background}

Leprosy is a chronic mycobacterial infection caused by Mycobacterium leprae leading to a plethora of clinical manifestations ranging from cutaneous manifestations to disfigurement, deformity, stigma, and disability (neurologic and blindness). The burden of disease associated with $M$. leprae infection in humans stems from the ability of this bacterial pathogen to induce severe injury of peripheral nerves (Schwann cells) and skin (keratinocytes and histiocytes) [1-7]. The clinical spectrum of disease of leprosy is further defined by the immune response to the leprosy bacillus ranging from tuberculoid, to borderline, and to lepromatous forms (Ridley-Jopling) [1, 2]. Once the infection is established, the occurrence of leprosy reactions, because of their inflammatory impact on the peripheral nerve, constitutes an important contributor to sensory loss and dysfunction $[2,3,8,9]$.

*Correspondence: carlos.franco.paredes@gmail.com

${ }^{1}$ Infectious Diseases Clinic, Phoebe Putney Memorial Hospital, 507 3rd

Avenue, Albany, GA 31721, USA

Full list of author information is available at the end of the article

\section{Leprosy trends}

Leprosy does not constitute the ancestral plague that once used to be. However, the elimination of leprosy as a public health problem as defined by the World Health Organization, has not been achieved in any meaningful and sustainable manner [6, 7]. Besides its measurable medical consequences, leprosy hampers the freedoms and capabilities of individuals and affected communities [10]; and often excludes individuals from social life due to the often associated stigma [11-13]. The early tales of fear and pity that leprosy in its severe forms elicited among many human groups, continues to transpire to a similar degree into modern societies $[6,7,13]$.

Leprosy continues to be an important infectious disease in many endemic settings as demonstrated by: (a) a growing number of new cases [7, 14, 15]; (b) many patients completing multi-drug therapy but subsequently developing leprosy reactions [16, 17]; or (c) microbiologically treated individuals but with long-term neurologic dysfunction and disability originated by irreversible peripheral nerve injury $[2,16]$.

Since 1981, multi-drug therapy (MDT) has been universally instituted through active case finding in highly affected communities [6, 14]. These programs have 
achieved some degree of success by decreasing the prevalence of the disease [14], however, there are many continuing challenges including: (a) yearly, new cases continue to be detected in highly endemic areas [7]; (b) since 2005, the number of reported new cases has remained consistently stable despite continuous use of MDT concomitantly with a substantial decrease in the prevalence of the disease [7]; (c) a rising number of new cases are expected to reach the 4 million mark by the year 2020 [7]; and (d) From 2007 to 2013, new cases continue to be identified with grade 2 disability with no evidence of this indicator decreasing [7].

There are two major potential reasons for the persistent detection of new cases of leprosy in endemic areas. The first one is that the "elimination phase" has transitioned into an era of complacency $[6,7,14]$. The reported rate of new case detections suggests that the rate of new cases decreased by $60 \%$ from 2000 to 2005 [7]. However, there is evidence to suggest that the detection of cases did not truly decreased to such degree during this period; and that current reports may actually represent an underestimation of newly detected cases [7]. Secondly, persistent transmission of $M$. leprae calls for reassessing our long-held notions about its mechanism and routes of transmission [18-20]. Current epidemiologic trends reinforce old disagreements regarding the portal of entry and the pathways of $M$. leprae into the human body $[19,20]$. Neither person-to-person transmission nor host-susceptibility explains the patchy distribution of leprosy, and new cases are detected in persons who have had no know contact with human leprosy (30-60\% of cases) $[5,6]$. Transmission of leprosy to close contacts has been documented and it is considered a major risk factor for developing leprosy among susceptible individuals [21-23]. Nonetheless, the precise mode and route of transmission has not been satisfactorily defined [22, 23]. It has been assumed that person-to-person transmission occurs by nasal secretions or cutaneous lesions under circumstances such as overcrowding, inadequate housing and lack of hygiene [21-23].

There is sufficient ecological data to suggest that the transmission of leprosy is potentially influenced by environmental factors such as soil and water exposures, insect vectors playing a role [24-35], and the free-living amoebas (e.g., Acanthamoeba spp.) may participate in the environmental viability of leprosy in some biotopes [30, 31]. Zoonotic transmission from natural infection of armadillos in the Southeast United States has been confirmed as responsible for the majority of autochthonous transmission of cases in this area [32]. It is likely that armadillos may also play an important role in the transmission of leprosy in some areas of Latin America such as in Colombia, Venezuela, Mexico, and Brazil [33].
Understanding how environmental factors influence host-pathogen interactions in complex natural systems $[34,35]$, where multiple feedbacks between biotic and abiotic factors take place, is especially important in the context of environmentally persistent pathogens such as M. leprae.

\section{Human migration and the spread of Mycobacterium leprae}

The mycobacterial ancestor of $M$. leprae diverged from the tuberculosis bacilli approximately 66 million years ago, long before the origin of the Homo genus [36-42]. Estimates of the intracellular adaptation of $M$. leprae related to reductive evolution and pseudogene development has been estimated to occur around 9 million years ago $[37,38]$. Our current understanding based on recent genetic and molecular clock data indicates that leprosy the human species prior or during the Paleolithic [37]. In turn, human migration has been crucial in the global spread of leprosy [38]. In this evolutionary journey, $M$. leprae has migrated with human populations through expeditionary, military, colonialist, and other human endeavours [38-41]. The earliest clinical descriptions of leprosy are said to be from Egypt and India from records dating back to 600 B.C.E [38]. Older descriptions of disfiguring cutaneous illnesses possibly including leprosy under the Hebrew Tsar'ath (zarath) contained in the Old Testament; however, this fact remains controversial since there is scant skeletal evidence for leprosy in human remains from Israel [13]. Humans are natural reservoirs in the transmission of $M$. leprae and therefore the global spread of leprosy is tied to historical milestones of human migration [10, 37-39]. Recent comparative genomic evidence points to the origin of the leprosy in Eastern Africa $[38,39]$. The cohabitation of $M$ leprae with human hosts has provided $M$. leprae with different social and biological attributes that facilitated the selection of different traits conferring different adaptive biological properties [37-39]. Phyleogeographic studies have demonstrated an association between the spread of leprosy and migration patterns of earlier human societies and trade routes (i.e., the Silk Road that united Europe to China contributed to the spread of leprosy) [38, 39, 41, 43]; or to historical events corresponding to the returning expeditionary forces of antiquity spreading the pathogen from the Middle-Eastern strain of M. leprae to Medieval Europe [38]. Subsequently, European explorers spread the disease westward to the New World or through the Atlantic slave route [37, 39]. Overall, genomic comparisons of ancient and modern strains of $M$. leprae remain remarkably similar, indicating it was probably improvements in social conditions that led to a substantial reduction of leprosy in Europe in the 16th Century [40, 41]. While these 
events indicate the crucial role of humans as reservoirs of disease and potentially transmitting to their close contacts, it is also feasible that nasal discharges or cutaneous lesions of populations migrating into previously leprosyfree biotopes may have caused a spillover of $M$. leprae into environmental niches with optimal biotic and abiotic factors that subsequently amplified the cycle of transmission of leprosy.

In modern times, it is likely that the clustering of cases of leprosy occurs among individuals living in resourcepoor areas with favorable ecological niches for M. leprae to thrive [21-23]. In turn, the human host acquires $M$. leprae by an increased exposure to mycobacteria by their low socioeconomic standing combined with their biologic susceptibility to acquire the infection and develop the disease. In these settings, poverty operates by promoting low schooling, poor housing in often-unstructured settlements with overcrowding, lack safe water, absence of water management systems and sewage, and, as a result most experience poor hygienic practices [21-23]. Additionally, most individuals who have been diagnosed with leprosy have also experienced food shortages and malnutrition. Suffering from leprosy and other neglected tropical diseases becomes part of their biological destiny and their way of life. Therefore, it is important to consider the larger social drivers that underlie the unequal distribution of life choices of individuals living in the highest endemic areas that place them at risk of suffering from leprosy and other neglected diseases.

\section{Mycobacterial ecology}

Humanity is irremediably imbedded in a matrix of natural and man-made ecologies of living organisms [44]. Mycobacteria are ubiquitous microorganisms that live in natural waters, soils, and engineered water systems that have role in nutrient cycling. A major determinant of the ecology and epidemiology of mycobacterial species is the presence of a lipid-rich outer membrane leading to biofilm formation, antibiotic/disinfectant resistance, aerosolization, and surface adherence [20,44]. A few species have evolved from this environmental pools to become major human pathogens such as M. tuberculosis, M. leprae and M. ulcerans [13, 45-49]. Searching for common ecological patterns and transmission dynamics among these three closely phylogenetically related species may assist in identifying environmental sources of persistent infection [45-49]. For the two major human pathogens, M. tuberculosis and M. leprae, it is crucial to adapt to the intracellular lifestyle and to modulate the lipid metabolism of sanctuary cells [44] (Table 1). M. tuberculosis and $M$. leprae have evolved pathogenic mechanisms through complex evolutionary negotiations between these pathogens and their hosts, while the acquisition of a large plasmid encoding the toxin mycolactone relates to the underlying mechanism of pathogenicity of $M$. ulcerans [48-50]. This mycobacterial pathogen is causative agent of Buruli ulcer, which is a chronic destructive necrotizing infection of subcutaneous tissue that has been reported to occur in more than 30 countries [48-50]. In contrast to M. tuberculosis and M. leprae, M. ulcerans adaptation mechanisms have involved the selection of certain genes that facilitate its livelihood occupying aquatic aerobic, dark, and osmotically stable environments and its ability to reside in the extracellular matrix of the subcutaneous tissues where it unleashes the production of its toxin [50]. Genetic analyses of $M$. ulcerans have shown that it had a common ancestor with $M$. marinum and that it diverged around a million years ago $[45,49,50]$. M. marinum produces a relatively milder nodular cutaneous lesions compared with Buruli ulcer [50].

Proverbial human-to-human transmission via respiratory droplets of $M$. leprae infection has been traditionally considered the driving engine of transmission of leprosy $[18,19,51,52]$. While leprosy bacilli are present in the nasopharynx of individuals with multibacillary leprosy [51] and from cutaneous lesions [52], and that these bacilli are able to infect other susceptible human hosts $[18,19]$, the precise mechanism and route of transmission remain to be completely elucidated. Indeed, the current epidemiology of the persistent transmission of leprosy along with collected evidence made since the 19th Century suggest that environmental factors such as soil and water, vegetation, arthropods [20], free-living amoebas [30,31], and animal reservoir host such as the nine-banded armadillo (Dasypus novemcintus) play an influential role in the ongoing transmission of $M$. leprae [32, 33].

In 1895, Hansen and Looft made the initial observation regarding the possibility of environmental factors involved in the transmission of leprosy [24]. They suggested that the initial site of cutaneous lesions often involved sites with direct contact with environmental surfaces (e.g., wading in streams and rivers in patients with lesions in calves). Subsequently, 27 years after Hansen's description of M. leprae, Sand proposed that the transmission of leprosy between humans takes place indirectly. His findings were the result of analyzing 1221 patients in the Norwegian leprosarium of Reitgjaerdet in whom the transmission within household was relatively low and most cases occurred in men who had more contact with environmental sources. He further proposed that perhaps a living organism or ground containing decomposing material were factors involved in the transmission cycle [25].

Environmental factors such as climate, type of soil and water, environmental degree of acidity [20], etc.; along 
Franco-Paredes and Rodriguez-Morales Ann Clin Microbiol Antimicrob (2016) 15:33

Page 4 of 10

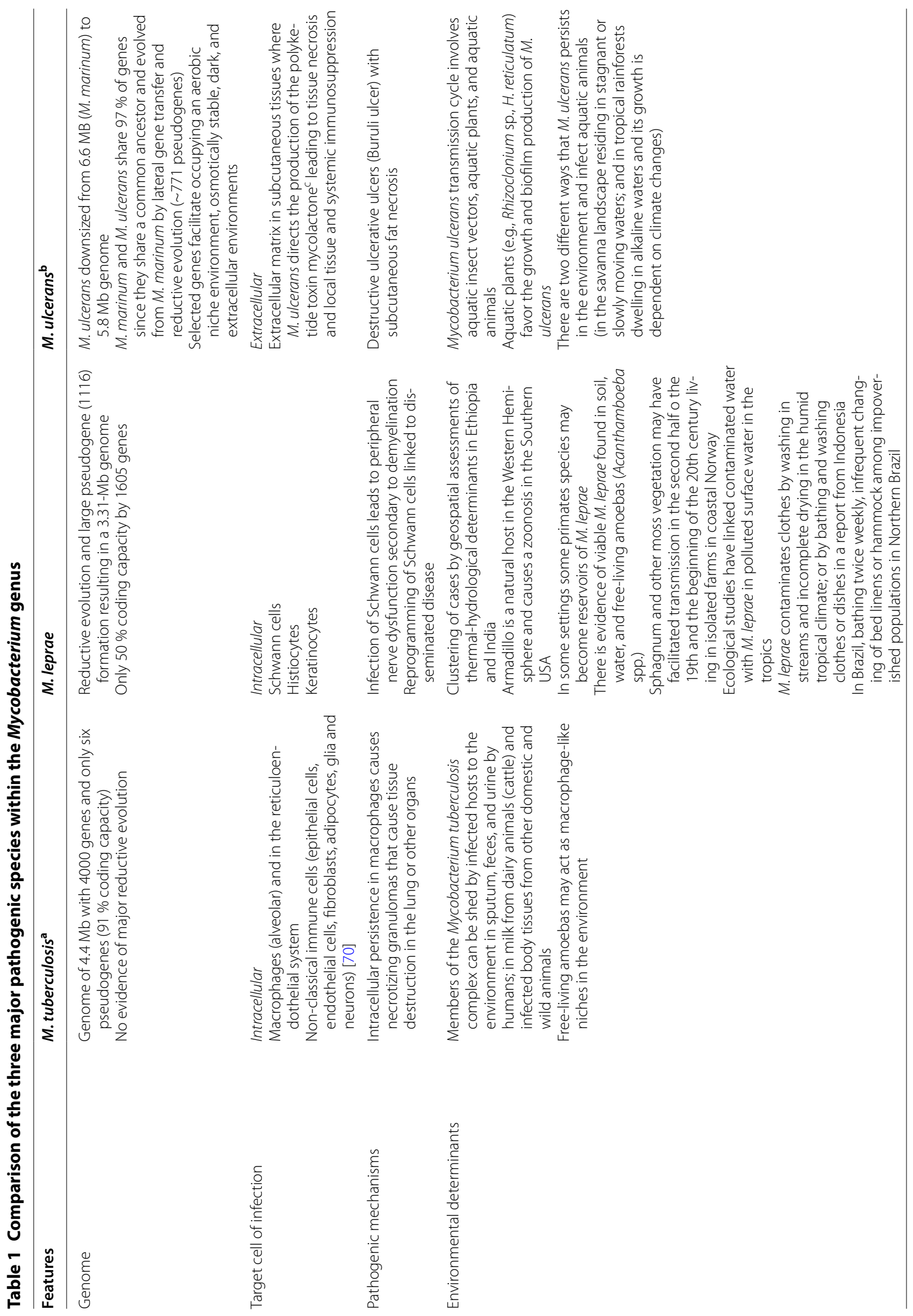




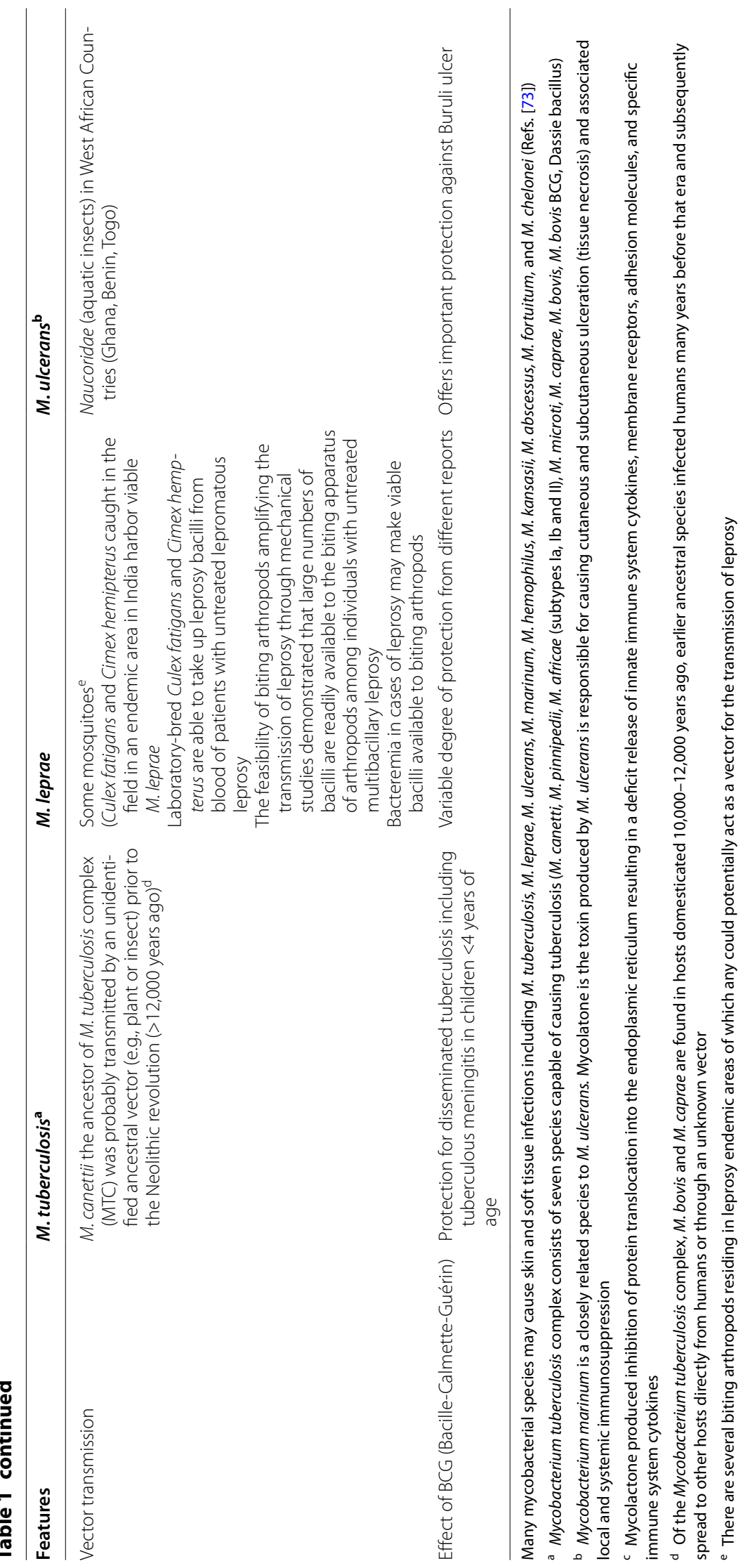


with spillover of M. leprae from human cases (e.g., nasal discharges contaminating soil or water) may facilitate the amplification of the transmission cycle in biotopes with existing suitable ecological abiotic and biotic determinants (i.e., tropical and subtropical settings) [34, 35]. In this hypothetical model, we can postulate that chemoprophylaxis (or preemptive treatment) of contacts of multibacillary cases and effective treatment of leprosy cases decreases spillage of $M$. leprae into environmental reservoirs (soil, water, plants, or free-living amoebas) [24, $25,27]$. Preliminary evidence from a leprosy-endemic area in India has shown that genetic material of M. leprae was detected near washing and bathing areas where cases of leprosy were detected and genetic fingerprinting correlated between human cases and DNA detected in soil samples [24, 29]. The spillover of $M$. leprae into soil and water may explain the acquisition of this pathogen by armadillos acting as scavengers, and ultimately linking a reverse cycle of transmission from armadillos back to humans [32]. Nevertheless, it is possible that there are other unidentified environmental reservoirs or vectors influencing the occurrence of new human infections in highly endemic areas. Zoonotic transmission of $M$. leprae from armadillos in the Golf Coast of the United States contributes to endemic human infections detected in this geographic area every year, supporting the fact that leprosy is not exclusively transmitted person-to-person [32].

\section{Free-living amoebas as environmental sanctuaries of $M$. leprae}

There is some evidence that the obligate intracellular $M$. leprae may spill over onto environmental niches and survive endosymbiotically inside free-living amoebae similar to the mechanism described of Legionella pneumophila residing inside Acanthamoeba [30,31]. Large numbers of viable leprosy bacilli are expelled into the environment in the nasal secretions or to a lower degree from skin lesions of individuals diagnosed with multibacillary leprosy [52]. There is also evidence that $M$. leprae may invade and infect the nasal mucosa or into abraded/punctured skin [52-54]. In this regard, it is feasible that free-living pathogenic amoebae potentially act as "external" reservoirs capable of ingesting and supporting the environmental viability of $M$. leprae expelled by infectious patients into the environment and thus acting as a macrophage-like niches [30, 31]. Further evidence has demonstrated that $M$. leprae remains viable for prolonged periods inside Acanthamoeba castellani and Acanthamoeba polyphaga; and it is able to survive encystment and retain infectivity in the nu/nu mouse model [33]. It remains to be tested if $M$. leprae infected amoebae is able to transport the bacilli through nasal mucosa or through intact or abraded skin to produce clinical disease [31].

\section{Arthropods as vectors of $\boldsymbol{M}$. leprae transmission}

The possibility of arthropods as vectors of M. leprae has not been conclusively ruled out [5]. As early as 1915, Adolpho Lutz suggested that "the erratic manner of the propagation of leprosy" might be explained by the bites of biting arthropods, particularly of Culex mosquitoes (i.e., Culex fatigans) [20]. In fact, there are several biting arthropods residing in highly endemic areas of leprosy that theoretically might act as a vector of M. leprae [5566]. In some studies, the distribution of single lesions of tuberculoid leprosy correlated with exposed skin areas [60, 61]. Mechanical studies have demonstrated the feasibility of biting arthropods to uptake M. leprae since large numbers of bacilli are readily available within cutaneous lesions to the biting apparatus of many species of arthropods among individuals with untreated multibacillary leprosy [59, 61-66]. Additionally, it has been shown that patients with lepromatous leprosy by developing bacteremia may make viable bacilli available to biting arthropods [63-65]. Sandflies have been ruled out as vectors of leprosy transmission [66].

There is evidence that mycobacterial species constituting the Mycobacterium tuberculosis complex (i.e., M. canetti) infected humans before the Neolithic period ( $<$ than 12,000 years ago) and that a non-mammalian vector may have played a role (e.g., plants or insects) [44-46]. Tuberculosis infection later spread to dairy animals as a result of human transmission during their domestication and involving a mechanism of transmission either through direct contact or through an unrecognized vector [44].

Mycobacterium ulcerans transmission cycle involves aquatic insect vectors, aquatic plants, and aquatic animals [45, 47-50]. Similarly, survival of $M$ leprae in environmental niches may also involve natural reservoirs (e.g., free-living amoebas) or it may be transmitted by arthropods (e.g., mosquitoes). It is also possible that species of the Mycobacterium tuberculosis complex may use environmental sanctuaries such as free-living amoebas to resist the external environment by acting as a macrophage-like niche [20]. Further studies using novel molecular assays need to be conducted to assess the potential contribution of arthropods to the transmission of leprosy in endemic areas.

\section{Early diagnosis and neurologic disability}

Peripheral nerve involvement occurs in all patients with $M$. leprae infection. At the time of a diagnosis of leprosy, up to $60 \%$ of cases have evidence of peripheral nerve damage enough to require prolonged course of corticosteroids [6]. Neural tropism of the leprosy bacillus is through its binding and entry into Schwann cells causing demyelination [8, 9, 67-69]. These events results in demyelination of myelinated Schwann cells that 


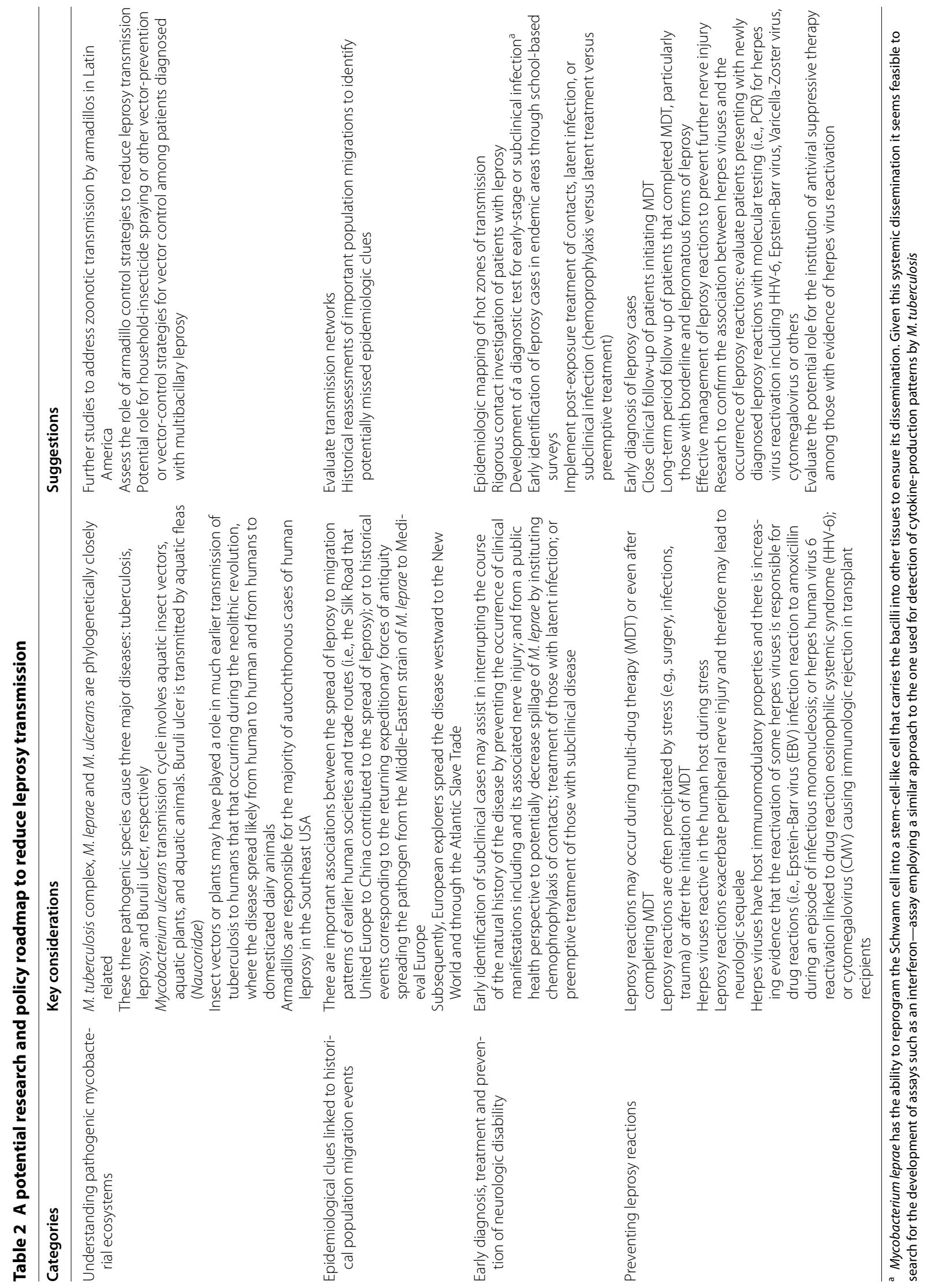


manifests clinically with decreased sensorimotor function and its associated complications [69, 70]. Additionally, M. leprae leads to a dedifferentiation process of Schwann cells transforming them into Trojan horses for the systemic dissemination of the bacilli $[3,69,70]$. Peripheral nerve sensorimotor dysfunction in patients with leprosy is frequently exacerbated by episodes of leprosy reactions $[8,9]$. Indeed, even after effective antibacterial therapy, a large number of dead bacterial cells remain within nerves and continue to elicit immunologic responses manifested as acute or chronic neuritis $[8,71]$. Early detection and treatment of neuropathy in leprosy has important preventive potential. Preventing leprosy reactions or effectively treating them is therefore an important consideration in any strategy attempting to reduce peripheral nerve injury. We need to expand our understanding of factors that predispose individuals to develop leprosy reactions and the mechanisms that trigger their occurrence. One important consideration is the potential role of the microbiome in modulating the inflammatory response, particularly of herpes viruses [2]. While there is little research in this area, there is ample evidence in other clinical scenarios to illustrate that herpes viruses modulate inflammatory responses during pathologic conditions [72] (Table 2). Early identification of leprosy cases remains a central priority in controlling this disease. In this regard, school-screening programs employing clinical assessments combined with serological and molecular surveys in endemic areas have been shown to increase the early detection of cases [73]. These programs have the greatest potential for reducing transmission by early instituting of treatment early in the course of the disease; and by identifying household contacts and household cases. Similarly, geospatial analyses of risk assessments of leprosy based on thermal and hydrological environments have demonstrated useful in predicting clustering of cases in studies conducted in Ethiopia and India [34, 35] (Table 2). Efforts to scale up school-based screenings and geospatial risk assessments based on ecological determinants in hyperendemic settings may offer so far, the best opportunity to reduce the occurrence of new cases.

\section{Conclusions}

Our understanding of the transmission dynamics of $M$. leprae is incomplete. While person-to-person transmission may play a role, there is a possibility of other modes of transmission involved. Therefore, there is a need for a fresh reexamination of the historical, phyleogeographic, sociocultural, and environmental factors linked to the spread of $M$. leprae among human populations. We need to consider mycobacterial ecologies of other pathogenic mycobacteria such as $M$. ulcerans; and to expand our exploration for environmental determinants including thermal-hydrological factors (i.e., soil, vegetation, water); intermediate reservoirs or vectors including free-living amoebas, arthropods, and zoonotic transmission. Identifying epidemiologic clues from these analyses may facilitate designing effective control or elimination interventions.

\section{Authors' contributions \\ CFP: Participated in the design, review of the literature, and writing of the manuscript. AJRM: Participated in the design, review of the literature, and writing of the manuscript. Both authors read and approved the final manuscript.}

\section{Author details \\ ${ }^{1}$ Infectious Diseases Clinic, Phoebe Putney Memorial Hospital, 507 3rd Avenue, Albany, GA 31721, USA. ${ }^{2}$ Hospital Infantil de México, Federico Gómez, Mexico D.F., Mexico. ${ }^{3}$ Public Health and Infection Research Group, Faculty of Health Sciences, Universidad Tecnológica de Pereira, Pereira, Risaralda, Colombia.}

\section{Competing interests}

The authors declare that they have no competing interests.

Received: 3 February 2016 Accepted: 11 May 2016

Published online: 21 May 2016

\section{References}

1. Britton WJ, Lockwood DNJ. Leprosy. Lancet. 2004;363:1209-19.

2. White $C$, Franco-Paredes C. Leprosy in the 21 st century. Clin Microbiol Rev. 2015;28(1):80-94.

3. Polycarpou A, Walker SL, Lockwood DN. New findings in the pathogenesis of leprosy and implications for the management of leprosy. Curr Opin Infect Dis. 2013;26:413-9.

4. Rodrigues LC, Lockwood DNJ. Leprosy now: epidemiology, progress, challenges, and research gaps. Lancet Infect Dis. 2011;11(6):464-70.

5. Gay FP. The unsolved problems in leprosy transmission. Science. 1935;81(2099):2083-5.

6. Lockwood DNJ, Shetty V, Oliveira Penna G. Hazards of setting targets to eliminate disease lessons from the leprosy elimination campaign. Brit Med J. 2014;348:g1136.

7. Smith WC, van Brakel W, Gillis T, Saunderson P, Richardus JH. The missing millions: a threat to the elimination of leprosy. PLoS Negl Trop Dis. 2015;9(4):e0003658.

8. Scollard DM, Truman RW, Ebenezer GJ. Mechanisms of nerve injury in leprosy. Clin Dermatol. 2015;33:46-54.

9. Scollard DM. The biology of nerve injury in leprosy. Lepr Rev. 2008;79:242-53.

10. Franco-Paredes C, Santos-Preciado JI. Freedoms, justice, and the neglected tropical diseases. PLoS Negl Trop Dis. 2011;5(8):e1235.

11. White C. Leprosy and stigma in the context of international migration. Lepr Rev. 2011;82(2):147-54.

12. Jacob J, Franco-Paredes C. The stigmatization of leprosy in India and its impact on future approaches to elimination and control. PLoS Negl Trop Dis. 2008;30:e113.

13. Stone AC, Wilbur AK, Buikstra JE, Roberts CA. Tuberculosis and leprosy in perspective. Am J Phys Anthropol. 2009;52:66-94.

14. Lockwood DNJ, Suneetha S. Leprosy: too complex a disease for a simple elimination paradigm. Bull World Health Org. 2005;83(3):230-5.

15. Smith CS, Kahder Noordeen S, Richardus JH, Sansarricq H, Cole ST, Baruaf S, Soares RS, Savioli L, Aertsh A. A strategy to halt leprosy transmission. Lancet Infect Dis. 2014;14:96-7.

16. Jacob J, Kozarsky P, Dismukes R, Bynoe V, Margoles L, Leonard M, Tellez I, Franco-Paredes C. Five-year experience with type 1 and type 2 reactions in Hansen's disease at a US travel clinic. Am J Trop Med Hyg. 2008;79:452-4. 
17. Pocaterra L, Jain S, Reddy R, Muzaffarullah S, Torres O, Suneetha S, Lockwood DNJ. Clinical course of erythema leprosum: an 11-year cohort study in Hyderabad, India. Am J Trop Med. 2006;74(5):868-79.

18. Bratschi MW, Steinmann P, Wickenden A, Gillis TP. Current knowledge on Mycobacterium leprae transmission: a systematic literature review. Lepr Rev. 2015;86:142-55.

19. Mensah-Awere D, Bratschi MW, Steinmann P, Fairley JK, Gillis TP. Developing straegies to block the transmission of leprosy. Lepr Rev. 2015;86:156-64.

20. Blake LA, West BC, Lary CH, Todd JR IV. Environmental nonhuman sources of leprosy. Rev Infect Dis. 1987;9(3):561-77.

21. Kerr-Pontes LRS, Barreto ML, Evangelist CMN, Rodrigues LC, Heukelbach J, Feldmeier H. Socioeconomic, environmental, and behavioural risk factors for leprosy in Northeast Brazil: results of a case-control study. Int J Epidemiol. 2006;35:994-1000.

22. Kerr-Pontes LRS, Montenegro ACD, Barreto ML, Werneck GL, Feldemeier H. Inequality and leprosy in Northeast Brazil: an ecological study. Int J Epidemiol. 2004;33:262-9.

23. Lockwood DNJ. Commentary: leprosy and poverty. Int J Epidemiol. 2004;33:269-70.

24. Lavania M, Katoch K, Katoch VM, Gupta AK, Chauhan DS, Sharma R, Gandhi R, Chauhan V, Bansal G, Sachan P, Sachan S, Yadav VS, Jadhav R. Detection of viable Mycobacterium leprae in soil samples: insights into possible sources of transmission of leprosy. Infect Genet Evol. 2008;8:627-31.

25. Kazda J, Pavlik I. Obligate pathogenic mycobacteria. In: Kazda J, Pavlik I, Falkinham JO, Hruska K, editors. The ecology of mycobacteria: impact on animal's and human's health. 2nd ed. Berlin: Springer; 2009. p. 1-19.

26. Sreevatsa. Leprosy and arthropods. Indian J Lepr. 1993;65(2):189-200.

27. Desikan KV, Sreevatsa. Extended studies on the viability of M. Leprae outside the human body. Lepr Rev. 1995;66:287-95.

28. Turankar RP, Lavania M, Singh M, Siva Sai KSR, Jadhav RS. Dynamics of Mycobacterium leprae transmission in environmental context: deciphering the role of environment as potential reservoir. Infect Gen Evol. 2012;12:121-6.

29. Matsuoka M, Izumi S, Budiawan T, Nakata N, Saeki K. Mycobacterium leprae DNA in daily using water as a possible source of leprosy infection. Indian J Lepr. 1999;71:61-7.

30. Lahiri R, Krahenbuhl JL. The role of free-living pathogenic amoeba in the transmission of leprosy: a proof of principle. Lepr Rev. 2008;79:401-9.

31. Wheat WH, Casali AL, Thomas V, Spencer JS, Lahiri R, Williams DL, McDonnell GE, Gonzalez-Juarrero M, Brennan PJ, Jackson M. Long-term survival and virulence of Mycobacterium leprae in amoebal cysts. PLoS Neglec Trop Dis. 2014;8(12):e3405.

32. Balamayooran G, Pena M, Sharma R, Truman RW. The armadillo as an animal model and reservoir host for Mycobacterium leprae. Clin Dermatol. 2015:33:108-15.

33. Cardona-Castro N, Beltran JC, Ortiz-Bernal A, Vissa V. Detection of Mycobacterium leprae DNA in nine-banded armadillos (Dasypus novemcinctus) from the Andean region of Colombia. Lepr Rev. 2009;80:424-31.

34. Tadesse Argaw A, Sannon EJ, Assefa A, Mikru FS, Mariam BK, Malone JB. A geospatial risk assessment model for leprosy in Ethiopia based on environmental thermal-hydrological regime analysis. Geospat Health. 2006;1 (1):105-13.

35. Joshua V, Mehendale S, Gupte MD. Bayesian model, ecologial factors and transmission of leprosy in an endemic area of South India. Indian J Med Res. 2016;143:104-6.

36. Gomez-Valero L, Rocha EPC, Latorre A, Silva F. Reconstructing the ancestor of Mycobacterium leprae: the dynamics of gene loss and genome reduction. Genome Res. 2007:17:1178-85.

37. Trueba G, Dunthorn M. Many neglected tropical diseases may have originated in the Paleolithic or before: new insights from genetics. PLoS Neglect Trop Dis. 2012;6(3):e1393.

38. Monot M, Honore N, Garnier T, Zidane N, Sherafi D, Paniz-Mondolfi A, Matsuoka M, Taylor GM, Donoghue HD, Bouwman A, Mays S, Wason C, Lockwood D, Khamesipour A, Dowlati Y, Jianping S, Rea TH, Vera-Cabrera L, Stefani MM, Banu S, Macdonald M, Spakota BR, Spencer JS, Thomas J, Harshman K, Singh P, Busso P, Gattiker A, Rougemont J, Brennan PJ, Cole ST. Comparative genomic and phyleogeographic analysis of Mycobacterium leprae. Nat Genet. 2009;41(12):1282-9.

39. Monot M, Honore N, Garnier T, Araoz R, Coppee JY, Lacroix C, Sow S, Spencer JS, Truman RW, Williams DL, Gelber R, Virmond M, Flageul B, Cho SN, Ji B, Paniz-Mondolfi A, Convit J, Young S, Fine PE, Rasolofo V, Brennan PJ, Cole ST. On the origin of leprosy. Science. 2005;308(5724):1040-2.
40. Singh P, Cole ST. Mycobacterium leprae: genes, pseudogenes, and genetic diversity. Future Microbiol. 2011;6(1):57-71.

41. Schuenemann VJ, Singh P, Mendum TA, Krause-Kyora B, Jager G, Bos Kl, Herbig A, Economou C, Benjak A, Busso P, Nebel A, Boldsen JL, Kjellstrom A, Wu H, Stewart GR, Taylor M, Bauer P, Lee OYC, Wu HHT, Minnikin DE, Besra GS, Tucker K, Roffey S, Sow SO, Cole ST, Nieselt K, Krause J. Genomewide comparison of medieval and modern Mycobacterium leprae. Science. 2013;341:179-83.

42. Prasanna AN, Mehra S. Comparative phylogenomics of pathogenic and non-pathogenic Mycobacterium. PLoS One. 2013;8(8):e71248.

43. Cardona-Castro N, Cortes N, Beltran C, Romero M, Badel-Mogollon JE, Bedoya G. Human genetic ancestral composition correlates with the origin of Mycobacterium leprae strains in a leprosy endemic population. PLoS Neglect Trop Dis. 2015;9(9):e0004045. doi:10.1371/journal. pntd.0004045.

44. Falkinham JO. Surrounded by mycobacteria: nontuberculous mycobacteria in the human environment. J Appl Microbiol. 2009;107(2):356-67.

45. Garchitorena A, Guegan JF, Lege L, Eyangoh S, Marsollier L, Roche B. Mycobacterium ulcerans dynamics in aquatic ecosystems are driven by a complex interplay of abiotic and biotic factors. eLife. 2015:4:e07616.

46. Boritsch EC, Supply P, Honore N, Seeman T, Stinear TP, Brosch R. A glimpse into the past and predictions for the future: the molecular evolution of the tuberculosis agent. Mol Microbiol. 2014;93(5):835-52.

47. Mostowy S, Behr MA. The origin and evolution of Mycobacterium tuberculosis. Clin Chest Med. 2005;26:207-16.

48. Marsollier L, Stinear T, Aubry J, Saint Andre JP, Robert R, Legras P, Manceau AL, Audrain C, Bourdon S, Kouakou H, Carbonnelle B. Aquatic plants stimulate the growth of and biofilm formation by Mycobacterium ulcerans in axenic culture and harbor these bacteria in the environment. Appl Environ Microbiol. 2004;70(2):1097-103.

49. Röltgen K, Stinear TP, Pluschke G. The genome, evolution and diversity of Mycobacterium ulcerans. Infect Genet Evol. 2012;12:522-9.

50. Doig KD, Holt KE, Fyfe JAM, Lavender CJ, Eddyani M, Portaels F, YeboahManu D, Pluschke G, Seeman T, Stinear TP. On the origin of Mycobacterium ulcerans, the causative agent of Buruli ulcer. BMC Genomics. 2012;13:258.

51. Davey TF, Res RJW. The nasal discharge in leprosy: clinical and bacteriological aspects. Lepr Rev. 1974;45:121-34.

52. Job CK, Jayakumar J, Kearney M, Gillis TP. Transmission of leprosy: a study of skin and nasal secretions of household contacts of leprosy patients using PCR. Am J Trop Med Hyg. 2008;78(3):518-21.

53. Chehl S, Job CK, Hastings RC. The nose: a site for the transmission of leprosy in nude mice. Am J Trop Med Hyg. 1985;34:1161-6.

54. Job CK, Harris EB, Allen JL, Hastings RC. Thorns in armadillo ears and noses and their role in the transmission of leprosy. Arch Pathol Lab Med. 1986;110:1025-8.

55. Dungal N. Is leprosy transmitted by arthropods? Lepr Rev. 1961;32:28-35.

56. Manja KS, Narayanan E, Kasturi G, Kirchheimer WF, Balasubramanyan M. Non-cultivable mycobacteria in some field collected arthropods. Lepr India. 1973:45:231-4.

57. Narayanan E, Sreevatsa, Kirchheimer WF, Bedi BMS. Transfer of leprosy bacilli from patients to mouse foot pads by Aedes aegypti. Lepr India. 1977:49:181-6.

58. Narayanan E, Sreevatsa, Raj AD, Kirchheimer WF, Bedi BMS. Persistence and distribution of M. leprae in Aedes aegyptii and Culex fatigans experimentally fed on leprosy patients. Lepr India. 1978;50:26-36.

59. Saha K, Jain M, Mukherjee MK, Chawla WM, Chaudhary DS, Prakash N. Viability of Mycobacterium leprae within the gut of Aedes aegypti after they feed on multibacillary lepromatous patients: a study by fluorescent and electron microscopes. Lepr Rev. 1985;56:279-90.

60. McDougall AC, Cologlu AS. Lepromatous leprosy in man; depth of the cellular infiltrate and bacillary mass in relation to the possibility of transmission of leprosy by biting arthropods. Ann Trop Med Parasitol. 1983;77(2):187-93.

61. Narayanan E, Manja KS, Bedi BM, Kirchheimer WF, Balasubrahmanyan M. Arthropod feeding experiment in lepromatous leprosy. Lepr Rev. 1972:43(4):188-93.

62. Kirchheimer WF. The role of arthropods in the transmission of leprosy. Int $J$ Lepr Other Mycobact Dis. 1976;44(1-2):104-7.

63. Manja KS, Bedi BM, Kasturi G, Kirchheimer WF, Balasubrahmanyan M. Demonstration of Mycobacterium leprae and its viability in the peripheral blood of leprosy patients. Lepr Rev. 1972;43(4):181-7. 
64. Sreevatsa, Sengupta U, Ramu G, Desikan KV. Evaluation of bacteraemia in leprosy patients. Lepr India. 1978;50(3):381-7.

65. Reis EM, Araujo S, Lobato J, Neves AF, Costa AV, Gonçalvez MA, Goulart LR, Goulart IMB. Mycobacterium leprae DNA in peripheral blood may indicate a bacilli migration route and high-risk for leprosy onset. Clin Microbiol Infect. 2014;20:447-52.

66. Sreevatsa, Girdhar BK. Can sandflies be the vector for leprosy? Int I Lepr Other Mycobact Dis. 1992;60(1):94-6.

67. Rambukkana A. Molecular basis for the peripheral nerve predilection of Mycobacterium leprae. Curr Opin Microbiol. 2001;4:21-7.

68. Lockwood DN, Saunderson PR. Nerve damage in leprosy: a continuing challenge to scientists, clinicians, and service providers. Int Health. 2012:4(2):77-85.

69. Masaki T, Qu J, Cholewa-Waclaw J, Burr K, Raaum R, Rambukkana A. Reprogramming adult Schwann cells to stem cell-like cells by leprosy bacilli promotes dissemination of infection. Cell. 2013;152(1-2):51-67.
70. Randall PJ, Hsu NJ, Quesniaux V, Ryffel B, Muazzam J. Mycobacterium tuberculosis infection of the 'non-classical immune cell'. Immunol Cell Biol. 2015:93:789-95.

71. Van Brakel WH, Nicholls PG, Wilder-Smith EP, Das L, Barkataki P, Lockwood DNJ. On behalf of the INFIR Study Group. PLoS Negl Trop Dis. 2008;2(4):e212.

72. Sorbara MT, Giardin SE. Emerging themes in bacterial autophagy. Curr Opin Microbiol. 2015;23:163-70.

73. Goncalvez Barreto J, Bisanzio D, Cipriani Frade MA, Pires Moraes TM Gobbo AR, de Souza Guimaraes L, et al. Spatial epidemiology and serologic cohorts increase the early detection of leprosy. BMC Infect Dis. 2015;15:527.

\section{Submit your next manuscript to BioMed Central and we will help you at every step:}

- We accept pre-submission inquiries

- Our selector tool helps you to find the most relevant journal

- We provide round the clock customer support

- Convenient online submission

- Thorough peer review

- Inclusion in PubMed and all major indexing services

- Maximum visibility for your research

Submit your manuscript at www.biomedcentral com/submit 